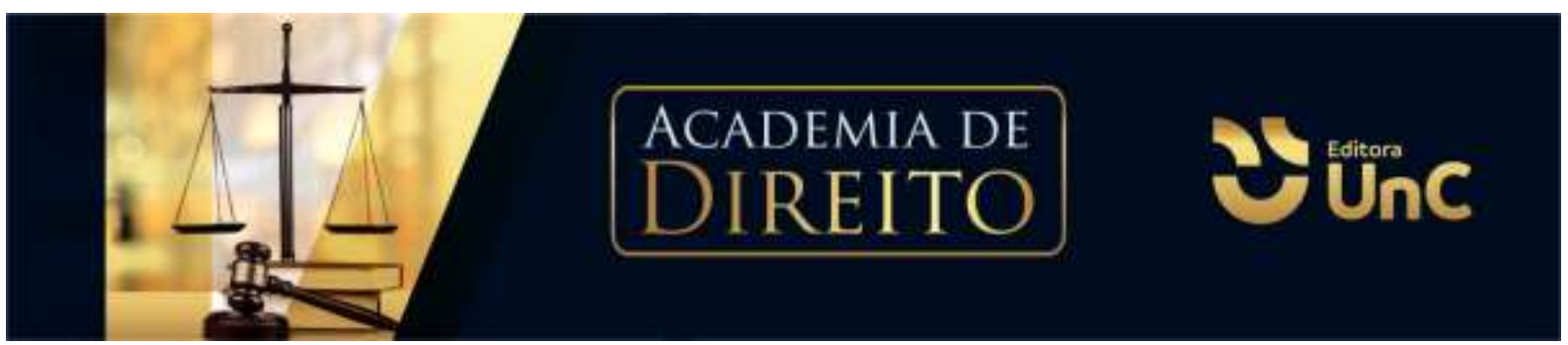

\title{
O DEVER LEGAL DE PROTEÇÃO AO IDOSO E A RESPONSABILIZAÇÃO DOS DESCENDENTES POR ABANDONO AFETIVO
}

\section{THE LEGAL DUTY TO PROTECT THE ELDERLY AND THE RESPONSIBILITY OF THE DESCENDANTS FOR AFFECTIVE ABANDONMENT}

Elisangela Magnani Ziemniczak ${ }^{1}$ Cilmara Corrêa de Lima Fante ${ }^{2}$

\begin{abstract}
RESUMO
À família cabe proporcionar um envelhecimento saudável, digno, tranquilo e principalmente afetivo, apoiado no dever recíproco de cuidado e respeito entre os familiares. Os idosos são pessoas que já contribuíram muito com a sociedade, contudo, para serem retribuídos de forma adequada, enfrentam muitas dificuldades pelo não reconhecimento do seu valor. Baseado nos dados estatísticos do envelhecimento da população brasileira e o dever legal da família na proteção do idoso, o presente artigo tem como objetivo geral pesquisar a possibilidade de responsabilização dos descendentes, por abandono afetivo do idoso, gerando indenização por dano moral. Considerando os objetivos específicos deste trabalho, serão estudados os seguintes temas: envelhecimento da população brasileira, o conceito de idoso, dever legal da família na proteção do idoso, responsabilidade por abandono afetivo, os precedentes jurisprudenciais relativo ao abandono afetivo e os projetos de lei que visam a responsabilização pelo abandono afetivo do idoso. A metodologia empregada foi o método dedutivo, com pesquisa bibliográfica e documental, a partir da consulta de artigos, legislação e jurisprudência.
\end{abstract}

Palavras-Chave: Idoso. Responsabilidade Civil. Abandono afetivo.

\begin{abstract}
The family is responsible for providing a healthy, dignified, peaceful and mainly affective aging, supported by the reciprocal duty of care and respect among family members. The elderly are people who have already contributed a lot to society, however, in order to be adequately compensated, they face many difficulties due to the lack of recognition of their value. Based on statistical data on the aging of the Brazilian population and the legal duty of the family to protect the elderly, the present article has the general objective of researching the possibility of responsibility of descendants, for
\end{abstract}

\footnotetext{
${ }^{1}$ Graduanda de Direito pela Universidade do Contestado. Campus Marcílio Dias. Canoinhas. Santa Catarina. Brasil. E-mail: lisamagnani77@gmail.com

${ }^{2} A d v o g a d a$, mestre em Desenvolvimento Regional pela Universidade do Contestado. Professora no curso de Direito da Universidade do Contestado. Santa Catarina. Brasil. E-mail: cilmarafante@unc.br
} 
the emotional abandonment of the elderly, generating indemnity for moral damage. Considering the specific objectives of this work, the following themes will be studied: aging of the Brazilian population, the concept of the elderly, the family's legal duty to protect the elderly, responsibility for affective abandonment, precedents in jurisprudence regarding affective abandonment and the bills that aim at accountability for the emotional abandonment of the elderly. The methodology used was the deductive method, with bibliographic and documentary research, based on the consultation of articles, legislation and jurisprudence.

Keywords: Elderly. Civil responsability. Affective abandonment.

\section{INTRODUÇÃO}

O presente estudo tem como objetivo retratar o processo de envelhecimento digno e a qualidade de vida da pessoa idosa, bem como fazer uma análise acerca do abandono afetivo na violação do dever de cuidado por parte dos filhos, provocando consequências irreparáveis na vida dos idosos, tanto físicas, mentais e sociais a gerar indenização por dano moral.

O cuidado e o bem estar do idoso deveriam ser o alicerce de sustentação da relação familiar, tendo em vista o zelo que o idoso teve para criar seus filhos até se tornarem adultos. Ao contrário disso, o idoso tem sido vítima de abandono pelos familiares e pela sociedade.

O amor é um sentimento que não deveria ser imposto, o cuidado e a atenção não deveria ser ato obrigatório e sim um ato de amor, gratidão e empatia. Cuidar é um dever constitucional e legal que não pode ser ignorado.

Entretanto, apesar do considerável avanço aos direitos dos idosos nos últimos anos, percebe-se que, em nossa sociedade, o abandono é uma realidade e que muitos idosos necessitam de proteção. Há quem culpe a rotina exaustiva do dia a dia, a jornada extensa de trabalho dos filhos, e assim a família deixa de dar a devida atenção para o idoso colocando na maioria das vezes em asilos ou com cuidadores, ou em outras famílias e até mesmo abandonados.

O estudo foi elaborado em três capítulos. Respectivamente o primeiro capítulo tratará do envelhecimento da população e o conceito da pessoa idosa dentro do ordenamento jurídico. No segundo momento, delinear-se-á o dever da família para com o idoso, na sequência aborda-se a responsabilidade civil por abandono afetivo 
bem como a interpretação jurisprudencial sobre o tema. Por fim serão apresentados alguns projetos de leis que tramitam na Câmara dos Deputados e no Senado Federal e visam a responsabilização pelo abandono afetivo do idoso por seus descendentes.

Para tanto formula-se a seguinte questão problema: Com base no envelhecimento da população brasileira e o dever legal da família na proteção do idoso é possível a responsabilização do descendente por abandono afetivo do idoso, gerando indenização por dano moral?

Para a realização da pesquisa utiliza-se o método dedutivo, serão utilizadas as técnicas de pesquisa bibliográfica e documental, a partir da consulta de doutrina, artigos, legislação e a jurisprudência.

\section{O ENVELHECIMENTO DA POPULAÇÃO BRASILEIRA E O CONCEITO DE IDOSO}

O envelhecimento humano é um processo caracterizado por inúmeras transformações, físicas, emocionais e sociais. Segundo Maria Berenice Dias, desde o início das civilizações o envelhecimento vem cercado de concepções, lendas, verdades, religiosidade, medos e incertezas, alternando-se entre as culturas e disputas de classes para que cada um possa definir o que vem a ser a velhice de modo geral (DIAS, 2016).

Contudo em 1970 em sua obra A Velhice, a escritora Simone de Beauvoir refere-se a velhice como resultado e o prolongamento de um processo, não estático, para ela o envelhecimento consistia na mudança continua.

\footnotetext{
Esta ideia está ligada a ideia de mudança. Mas a vida do embrião, do recémnascido, da criança, é uma mudança contínua. Caberia concluir daí, como fizeram alguns, que nossa existência é uma morte lenta? É evidente que não. Um tal paradoxo desconhece a essencial verdade da vida; esta é um sistema instável, no qual cada instante, o equilíbrio se perde e se reconquista: é a inércia que é sinônimo da morte. Mudar é a lei da vida. É um certo tipo de mudança que caracteriza o envelhecimento: irreversível e desfavorável - um declínio (BEAUVOIR, 2018, n.p.)
}

Nessa concepção a juíza e escritora Andréa Pacha, em seu artigo para o Jornal O Globo, alerta que a sociedade que eleva a juventude, que nega a doença e a tristeza, bem como o envelhecimento e pôr fim a morte não é exatamente o melhor 
ambiente para compreender a importância da velhice e da passagem do tempo (PACHA, 2018).

De acordo com estudo realizado pela Secretaria Especial do Ministério do Desenvolvimento Social, a população idosa (com 60 anos ou mais de idade), vem aumentando anualmente de um modo significativo no Brasil, segundo a pesquisa esses cidadãos são usuários dos serviços sociais, de saúde, de proteção e que precisam ter os seus direitos garantidos, o que viabiliza a proteção jurídica por meio do Estado, seguida da família e da sociedade (BRASIL. MINISTÉRIO DO DESENVOLVIMENTO SOCIAL, 2018).

Baseado nos dados publicados pelo Instituto Brasileiro de Geografia e Estatística - IBGE a taxa de mortalidade relacionado com o aumento da longevidade, são os fatores que causam a inversão da pirâmide etária, agindo como estimulantes no processo de transformação do envelhecimento em um problema social. A idade avançada carrega ao seu lado vulnerabilidades, sendo indispensável à extensão da sociabilização e da proteção às pessoas de mais idade (BORGES; ERVATI; JARDIM, 2015).

O gráfico nos mostra a mudança da pirâmide etária em relação os anos de 1980 até 2060. O IBGE nos aponta que, aproximadamente 1/3 da população brasileira será de pessoas idosas (BRASIL. MINISTÉRIO DO DESENVOLVIMENTO SOCIAL, 2018).

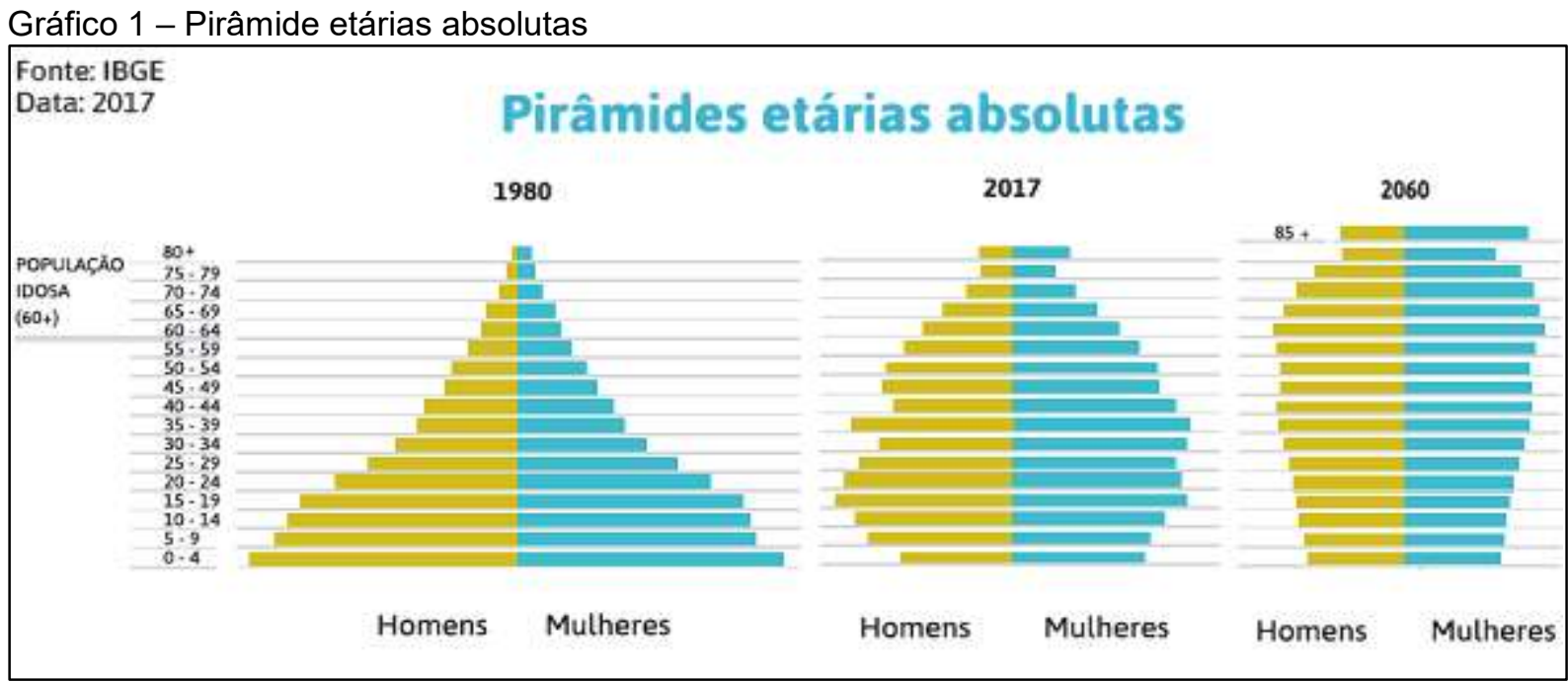

Fonte: Borges; Ervatti; Jardim (2015) apud Brasil. Ministério do Desenvolvimento Social (2018). 
Para Gabriel Mendes Borges, Marden Barbosa Campos e Luciano Gonçalves de Castro o segmento populacional que mais aumenta na população brasileira é o de idosos, com taxas de crescimento de mais de 4\% ao ano no período de 2012 a 2022. A população com 60 anos ou mais de idade passa de 14,2 milhões, em 2000, para 19,6 milhões, em 2010, devendo atingir 41,5 milhões, em 2030, e 73,5 milhões, em 2060. Espera-se, para os próximos 10 anos, um incremento médio de mais de 1,0 milhão de idosos anualmente. Essa situação de envelhecimento populacional é consequência, primeiramente, da rápida e contínua queda da fecundidade no País, além de ser também influenciada pela queda da mortalidade em todas as idades (BORGES; CAMPOS; SILVA, 2015).

Diante do cenário que se apresenta o envelhecimento populacional apurado no Brasil estabelece simultaneamente um triunfo e um desafio de intensidade jamais enfrentada, desdobrando inúmeras implicações sociais, econômicas, culturais, políticas e também, consequências na qualidade de vida dos idosos.

Tem-se como grande desafio mudar paradigmas, sendo que envelhecer implica em regular constantemente um lento processo de perdas físicas, psicológicas e cognitivas. Para uma velhice saudável dependerá muito da aceitação dessa circunstância. O sistema cronológico conceitua idoso levando em consideração os anos vividos, circunstância naturalmente comprovado através de certidão de nascimento.

O envelhecimento é o tempo de vida do homem em um corpo que sofre muitas mutações de aparência e declínio de força e disposição. Porém, a idade cronológica não parece o único meio legitimo para situar as pessoas no tempo. Entende-se que com os passar dos anos os idosos fiquem debilitados com déficits e algumas vezes de declínio cognitivo, por essa razão a presença da família é de suma importância, para detectar essas limitações e com a devida importância que o idoso necessitado e devidamente valorizados, possam ter as intervenções propostas para uma vida saudável (BRAGA, 2011).

Para Maria Berenice Dias (2016, p. 1101).

A palavra velho é considerada politicamente incorreta e dispõe de conteúdo ofensivo. Daí o uso do vocábulo idoso que também guarda conotação pejorativa. Por isso, há uma série de expressões que tentam suavizar a identificação das pessoas que somente deixaram de ter plena capacidade 
competitiva na sociedade: terceira idade, melhor idade, adulto maduro, adulto maior etc. Até parece que suavizar tais palavras vai fazer alguns anos desaparecer. Mas é quase como a expressão usada com relação aos automóveis. Não mais se usa carro usado e sim seminovo, ainda que o carro seja o mesmo!

Utiliza-se o termo idoso negativamente como velho, decadente, antigo, atribuído pela sociedade imposta por tabus de juventude e beleza, fazendo com que muitos esqueçam que a idade não é sinônimo de capacidade e sim de amadurecimento e experiências que podem ser compartilhadas com os mais jovens que se julgam mais ativos e perspicazes (VIEGAS; BARROS, 2016).

Segundo Andréa Pachá, com ou sem autorização e contra os desejos da pessoa humana, o tempo age e o corpo gasta. Ninguém deseja morrer jovem, a longevidade, no entanto, tem posto conflitos complexos na vida, os impactos no cotidiano são inevitáveis, com reflexos na estrutura física, mental, econômica e cultural. Não há como fugir dos déficits de vulnerabilidade ou dependência, portanto é preciso valorizar a autonomia dos idosos, pois assim seremos invariavelmente em poucas décadas (PACHÁ, 2018).

Nos tempos atuais, valoriza-se muito a produtividade dessa forma constroem a ideia de que sendo velho não pode mais produzir mais nada, investindo assim valores negativos aos idosos, transformando a velhice em algo indesejável, fazendo com que o idoso perca sua vontade de produzir e tomar conta de seus bens e riquezas desmotivando sua inclusão no meio social.

\section{DEVER LEGAL DA FAMÍLIA NA PROTEÇÃO DO IDOSO}

Muitas mudanças ocorreram em benefício das garantias inerentes à pessoa idosa, por meio das legislações existentes a partir dos preceitos Constitucionais, percebe-se que a família tem o dever de zelo por cada um de seus integrantes, em especial pelos idosos.

Consequentemente na relação entre os membros familiares, em especial aos filhos capazes em relação aos pais, Ihes cabe oferecer um ambiente propício a um envelhecimento tranquilo e sereno, sendo que isso só é possível quando esses integrantes asseguram aos seus pais um envelhecimento ativo e participativo. 
Os membros da família devem ser o ponto de apoio do bem-estar do idoso em todas as circunstâncias da vida, a proteção ao idoso está em diversos instrumentos normativos independentes, porém complementares (SOMMER; OLIVEIRA; DUARTE, 2017).

Evidencia-se na Constituição Federal artigo $203^{3}$ o benefício assistencial do idoso deve ser prestado em situação de vulnerabilidade econômica e na sequência os artigos $229^{4}$ e $230^{5}$ apontam que a família tem o dever de amparar as pessoas idosas e com isso necessário que sua participação na sociedade seja feito pela família, ou seja, a família como pilar na vida da pessoa idosa tem o dever de inclusão, com isso defendendo sua dignidade e bem-estar e garantindo-lhes o direito à vida (RAMOS, 2014).

A dignidade da pessoa humana conduz o respeito a todos os integrantes da família em especial ao idoso, de forma individual faz-se necessário à criação de mecanismos pelo Estado para que o idoso tenha seus direitos garantidos.

Corrobora-se a lição de Maria Berenice Dias (2016, p. 74-75).

A dignidade da pessoa humana encontra na família o solo apropriado para florescer. A ordem constitucional dá-lhe especial proteção independentemente de sua origem. A multiplicação das entidades familiares preserva e desenvolve as qualidades mais relevantes entre os familiares - 0 afeto, a solidariedade, a união, o respeito, a confiança, o amor, o projeto de vida comum -, permitindo o pleno desenvolvimento pessoal e social de cada partícipe com base em ideais pluralistas, solidaristas, democráticos e humanistas.

\footnotetext{
${ }^{3}$ Art. 203. A assistência social será prestada a quem dela necessitar, independentemente de contribuição à seguridade social, e tem por objetivos:

I - a proteção à família, à maternidade, à infância, à adolescência e à velhice;

II - o amparo às crianças e adolescentes carentes;

III - a promoção da integração ao mercado de trabalho;

IV - a habilitação e reabilitação das pessoas portadoras de deficiência e a promoção de sua integração à vida comunitária;

$V$ - a garantia de um salário mínimo de benefício mensal à pessoa portadora de deficiência e ao idoso que comprovem não possuir meios de prover à própria manutenção ou de tê-la provida por sua família, conforme dispuser a lei.

${ }^{4}$ Art. 229. Os pais têm o dever de assistir, criar e educar os filhos menores, e os filhos maiores têm o dever de ajudar e amparar os pais na velhice, carência ou enfermidade.

${ }^{5} \mathrm{Art}$. 230. A família, a sociedade e o Estado têm o dever de amparar as pessoas idosas, assegurando sua participação na comunidade, defendendo sua dignidade e bem-estar e garantindo-lhes o direito à vida (BRASIL,1988)
} 
Com efeito, a solidariedade acaba repercutindo na relação familiar e consequentemente no respeito recíproco determinando a cada membro da família deveres de sustentação, assistência e cuidado (LEITE, 2018).

Segundo Pablo Stolze Gagliano e Rodolfo Pamplona Filho (2017, p. 188).

\begin{abstract}
Um tratamento respeitoso e preferencial aos idosos é, sem dúvida, um verdadeiro dogma na disciplina atual das relações de família. A devida reverência a todos aqueles que sobreviveram às batalhas da vida e, agora, encontram menos vigor em seus corpos físicos é um imperativo de justiça e uma decorrência necessária do princípio geral da proteção à dignidade da pessoa humana, bem como, em especial, do princípio da solidariedade social.
\end{abstract}

Manifestada no respeito, a afetividade proporciona estabilidade aos mais vulneráveis, como os idosos, o bem-estar psíquico tem grande influência nas suas vidas, na vontade e a alegria de viver, de estar perto de quem se ama, sendo no convívio junto a família ou aos amigos, eleva-se a autoestima e garante aumento na expectativa e qualidade de vida.

Em virtude do constante avanço do número da população idosa, entende-se que, com ou sem a autorização das pessoas e contra o desejo dela, o tempo age e o corpo gasta, com ou sem rugas aparentes. Levando em conta a conjuntura de vulnerabilidade, fragilidade e insegurança que os idosos se encontram com a chegada da terceira idade, o nosso ordenamento jurídico julgou necessário lançar uma tutela específica sobre eles, o Estatuto do Idoso ajustando as legislações e criando dispositivos de proteção (PACHA, 2018).

Ademais aos preceitos constitucionais consubstanciados na proteção e valorização do idoso, a Lei $n^{\circ} 10.741 / 03$ Estatuto do Idoso obriga o Estado, a sociedade e a família quanto à efetivação destes direitos ${ }^{6}$.

Reconhece-se no Estatuto do Idoso a fragilidade da pessoa idosa e a necessidade de assegurar-Ihes proteção integral, em todos os aspectos de sua vida, permitindo que seus últimos anos sejam vividos em sua plenitude, condizente com a dignidade da pessoa humana, refletindo, inclusive, os ideais de justiça social (ARRUDA; BORGES, 2016).

\footnotetext{
${ }^{6}$ Art. 3o É obrigação da família, da comunidade, da sociedade e do Poder Público assegurar ao idoso, com absoluta prioridade, a efetivação do direito à vida, à saúde, à alimentação, à educação, à cultura, ao esporte, ao lazer, ao trabalho, à cidadania, à liberdade, à dignidade, ao respeito e à convivência familiar e comunitária (BRASIL, 2003).
} 
Não obstante a obrigação prevista no Estatuto, não ser tratar de faculdade, evidencia-se o dever moral e afetivo que muitas vezes são negligenciados, havendo a necessidade de recorrer ao Estado para a efetiva tutela de direitos conferido ao idoso, responsabilizando os filhos a prestação de cuidados com seus pais na velhice, transparecendo assim a reciprocidade e reconhecimento com quem lhes ofertou amparo integral, físico e psíquico, quando eram frágeis e vulneráveis.

Para Paulo Lôbo (2019), o idoso é cidadão vulnerável, merecedor tanto da proteção do Estado como da família e da sociedade, a legislação tem de oferecer os meios necessários para que essa proteção se efetive, pois as necessidades dos idosos são de fato necessidades pertencentes à vida humana, pois é feito que um dia todos cheguem à velhice.

Para tanto, segundo Lôbo, nas relações familiares, considera-se o afeto um valor jurídico, reunindo princípios que vão além de amor e carinho, relacionando-se sempre com a medida apropriada de cuidado, dedicação, auxílio (LOBO, 2019).

Liga-se $o$ afeto a convivência familiar, tornando-se um alicerce na vida das pessoas, um porto seguro, em especial ao idoso, que no processo de envelhecimento tornam-se cada vez mais vulneráveis.

Nessa seara, cabe à família, ao Estado e a sociedade apoiar as definições e preferências do idoso, ainda que não concordem, sendo que apenas em casos de incapacidade, comprovados judicialmente, possam interferir na sua própria vontade. Uma vez evidenciada a realidade que está inserido o idoso na legislação brasileira, torna-se explícita a sua vulnerabilidade diante da sociedade e a inevitabilidade do nosso ordenamento jurídico promover maior proteção àqueles que atingem a velhice, 
conforme preceituado pelo Estatudo do Idoso em seus artigos $10^{7}$ e $17^{8}$ (BRASIL, 2003).

\section{RESPONSABILIDADE POR ABANDONO AFETIVO DO IDOSO}

Segundo Rodrigo da Cunha Pereira entende-se por responsabilidade civil como uma obrigação de reparar danos, isto é, ressarcir o indivíduo como consequência do direito violado. Ele explica que a responsabilidade civil remete a ideia das consequências danosas da conduta ao agente infrator, sendo indispensável à existência de um dano, pois sem a ocorrência deste elemento não haveria o que indenizar (CUNHA, 2020).

O ordenamento brasileiro disciplina a responsabilidade civil quando alguém, por ação ou omissão, causar dano a outrem, de modo que terá que repará-lo, conforme disposto no artigo $927^{9}$ do Código Civil. Também comete ato ilícito quem por ação ou omissão voluntária, negligência ou imprudência causar dano a outrem, ainda que exclusivamente moral segundo artigo $186^{10}$ do Código Civil (BRASIL, 2002).

\footnotetext{
${ }^{7}$ Art. 10. É obrigação do Estado e da sociedade, assegurar à pessoa idosa a liberdade, o respeito e a dignidade, como pessoa humana e sujeito de direitos civis, políticos, individuais e sociais, garantidos na Constituição e nas leis.

$\S 1$ O O direito à liberdade compreende, entre outros, os seguintes aspectos:

I - faculdade de ir, vir e estar nos logradouros públicos e espaços comunitários, ressalvadas as restrições legais;

II - opinião e expressão;

III - crença e culto religioso;

IV - prática de esportes e de diversões;

$\checkmark$ - participação na vida familiar e comunitária;

VI - participação na vida política, na forma da lei;

VII - faculdade de buscar refúgio, auxílio e orientação.

${ }^{8}$ Art. 17. Ao idoso que esteja no domínio de suas faculdades mentais é assegurado o direito de optar pelo tratamento de saúde que lhe for reputado mais favorável.

Parágrafo único. Não estando o idoso em condições de proceder à opção, esta será feita:

I - pelo curador, quando o idoso for interditado;

II - pelos familiares, quando o idoso não tiver curador ou este não puder ser contactado em tempo hábil;

III - pelo médico, quando ocorrer iminente risco de vida e não houver tempo hábil para consulta a curador ou familiar;

IV - pelo próprio médico, quando não houver curador ou familiar conhecido, caso em que deverá comunicar o fato ao Ministério Público.

${ }^{9}$ Art. 927. Aquele que, por ato ilícito, causar dano a outrem, fica obrigado a repará-lo.

Parágrafo único. Haverá obrigação de reparar o dano, independentemente de culpa, nos casos especificados em lei, ou quando a atividade normalmente desenvolvida pelo autor do dano implicar, por sua natureza, risco para os direitos de outrem.

${ }^{10} \mathrm{Art}$. 186. Aquele que, por ação ou omissão voluntária, negligência ou imprudência, violar direito e causar dano a outrem, ainda que exclusivamente moral, comete ato ilícito.
} 
A função da responsabilidade civil é garantir o direito cuja pessoa foi lesionada, garantindo-lhe segurança e servindo como penalidade civil, visando à restauração do dano causado, para que o infrator, sendo punido, possa ter a consciência do mal causado e não volte cometer o mesmo erro.

Para Silvio de Salvo Venosa (2019, p. 443).

\begin{abstract}
No vasto campo da responsabilidade civil, o que interessa saber é identificar aquela conduta que reflete na obrigação de indenizar. Nesse âmbito, uma pessoa é responsável quando suscetível de ser sancionada, independentemente de ter cometido pessoalmente um ato antijurídico. Nesse sentido, a responsabilidade pode ser direta, se diz respeito ao próprio causador do dano, ou indireta, quando se refere a terceiro, o qual, de uma forma ou de outra no ordenamento, está ligado ao ofensor. Se não puder ser identificado o agente que responde pelo dano, este ficará irressarcido; a vítima suportará o prejuízo. O ideal, porém, que se busca no ordenamento, é no sentido de que todos os danos sejam reparados.
\end{abstract}

O primeiro pressuposto da responsabilidade civil é a conduta humana, comissivo ou omissivo. Segundo Flávio Tartuce (2020), a conduta humana e a culpa podem ser considerados como um só elemento subjetivo da responsabilidade civil, consequentemente a conduta humana pode ser causada por uma ação ou omissão, voluntária ou por negligência, imprudência ou imperícia, definindo o dolo e a culpa, nota-se que a regra é a ação ou conduta positiva e que para a configuração da omissão indispensável que exista o dever jurídico de praticar determinado ato.

Outro pressuposto à caracterização da responsabilidade civil é o dano, segundo Sergio Cavalieri Filho a reparação só ocorre quando alguém pratica ato ilícito e causa dano a outra pessoa. Não basta somente o risco de dano e a conduta ilícita, sem uma consequência corpórea, não se determina o dever de reparar (CAVALIERI, 2019).

Como elemento de conexão entre a conduta do agente e o dano, tem-se o nexo de causalidade. Para Tartuce (2020, n.p.), "nexo causal constitui o elemento imaterial ou virtual da responsabilidade civil, constituindo a relação de causa e efeito entre a conduta culposa ou o risco criado e o dano suportado por alguém".

Para a configuração da responsabilidade civil por abandono afetivo do idoso, o dano deverá ser evidente, comprovando-se a inexistência do afeto, sentimento este que deveria fazer parte das relações familiares, a negligência no dever de cuidado que deve existir entre às pessoas, de maneira especial no seio familiar, pois como 
ensina Andréa Pachá, não basta somente o amparo material para garantir uma vida digna, há também o amparo afetivo, como carinho, amor, cuidado, dedicação e respeito (PACHÁ, 2018).

Este é o pensar de Maria Berenice Dias (2016, p.1110-1111).

\begin{abstract}
Como o avançar da idade gera a necessidade de mais cuidados e maior atenção, muitas vezes os idosos passam a ser considerados um estorvo. Os familiares têm suas próprias famílias, precisam trabalhar e, no mais das vezes, não têm mais nem tempo e nem paciência para cuidar de quem os cuidou durante toda uma vida. A terceirização de tais encargos - quer com a contratação de pessoas nem sempre qualificadas ou a remoção para as chamadas casas de repouso - acaba relegando o idoso ao esquecimento. Filhos, netos e demais parentes deixam de visitá-lo, principalmente quando a comunicação entre eles é dificultada pelas limitações próprias da idade. E a falta de afeto e estímulo só debilita ainda mais quem se tornou frágil e carente com o avanço dos anos. Flagrada esta realidade, há que se reconhecer a ocorrência de abandono afetivo, de nefastas consequências já admitidas pela justiça, quando a omissão diz com crianças e adolescentes. Quando se trata de pessoa idosa, chamasse de abandono afetivo inverso: o inadimplemento dos deveres de cuidado e afeto dos descendentes para com os ascendentes, conforme impõe a Constituição Federal em seu art. 229.
\end{abstract}

Contudo, o afeto não está sujeito à imposição, no entanto evidencia-se a repercussão de pedidos indenizações por abandono afetivo nos Tribunais, com decisões relevantes no que concernem ao abandono afetivo da criança e do adolescente, servindo de paradigma para a aplicação judicial da responsabilidade civil por abandono afetivo do idoso.

\title{
4.1 PRECEDENTES JURISPRUDENCIAIS RELATIVO AO ABANDONO AFETIVO
}

O Superior Tribunal de Justiça e alguns Tribunais Estaduais já vem caracterizando a aplicabilidade da responsabilidade civil no direito de família. Alguns julgados vêm trazendo acolhimentos com as pretensões de ações de abandono afetivo, movidas pelos filhos contra os pais.

No entanto, é possível encontrar diferentes posicionamentos, resumidos em duas formas de pensar bem distintas. Uma delas defende que não haverá reparação pecuniária por abandono afetivo, pelo simples fato de que ninguém pode ser obrigado a amar. A segunda defende a ideia da existência da responsabilidade civil com indenização por danos morais pelo desamparo, pela ausência de auxílio, de solidariedade e de afeto. 
Com isto, o Colendo Superior Tribunal de Justiça se manifestou sobre o tema, reconhecendo a possibilidade de valorar juridicamente o afeto na relatoria da Ministra Nancy Andrighi, da $3^{\circ}$ Turma, admitindo a indenização por dano moral em face do abandono afetivo dos pais.

\begin{abstract}
CIVIL E PROCESSUAL CIVIL. FAMÍLIA. ABANDONO AFETIVO. COMPENSAÇÃO POR DANO MORAL. POSSIBILIDADE. 1. Inexistem restrições legais à aplicação das regras concernentes à responsabilidade civil e o consequente dever de indenizar/compensar no Direito de Família. 2. O cuidado como valor jurídico objetivo está incorporado no ordenamento jurídico brasileiro não com essa expressão, mas com locuções e termos que manifestam suas diversas desinências, como se observa do art. 227 da $\mathrm{CF} / 88$. 3. Comprovar que a imposição legal de cuidar da prole foi descumprida implica em se reconhecer a ocorrência de ilicitude civil, sob a forma de omissão. Isso porque o non facere, que atinge um bem juridicamente tutelado, leia-se, o necessário dever de criação, educação e companhia - de cuidado - importa em vulneração da imposição legal, exsurgindo, daí, a possibilidade de se pleitear compensação por danos morais por abandono psicológico. 4. Apesar das inúmeras hipóteses que minimizam a possibilidade de pleno cuidado de um dos genitores em relação à sua prole, existe um núcleo mínimo de cuidados parentais que, para além do mero cumprimento da lei, garantam aos filhos, ao menos quanto à afetividade, condições para uma adequada formação psicológica e inserção social. 5. A caracterização do abandono afetivo, a existência de excludentes ou, ainda, fatores atenuantes - por demandarem revolvimento de matéria fática - não podem ser objeto de reavaliação na estreita via do recurso especial. 6. A alteração do valor fixado a título de compensação por danos morais é possível, em recurso especial, nas hipóteses em que a quantia estipulada pelo Tribunal de origem revela-se irrisória ou exagerada. 7. Recurso especial parcialmente provido (BRASIL, 2012)
\end{abstract}

No caso julgado, o primeiro a reconhecer a possibilidade da compensação do dano moral sofrido pelo abandono afetivo, a autora entrou com ação contra o pai, após ter sua identidade reconhecida pela justiça, por ter sofrido abandono afetivo e material durante toda sua vida.

Através destas palavras, "Amar é faculdade, cuidar é dever”, a Ministra Nancy Andrighi certificou a possibilidade de exigir indenização por dano moral decorrente de abandono afetivo e mais adiante destaca que: "Muitos, calcados em axiomas que se focam na existência de singularidades na relação familiar sentimentos e emoções, negam a possibilidade de se indenizar ou compensar os danos decorrentes do descumprimento das obrigações parentais a que estão sujeitos os genitores." (BRASIL, 2012, p. 7).

A Ministra complementa sua análise técnica, a Constituição Federal e o Código Civil no qual amparam o tema relativo a danos morais de forma ampla, 
regulando inclusive os intrincados meandros das relações familiares. Ela defende que nas relações familiares, o dano moral pode envolver questões subjetivas, como afetividade, mágoa, amor entre outros (BRASIL, 2012).

Pela Turma ficou decidido que o valor pelos danos morais fixado pelo TJSP foi muito elevado e reduziu o valor para $\mathrm{R} \$ 200.000,00$ (duzentos mil reais), com voto vencido do Ministro Massami Uyeda, contrário a indenização, justificando que a posição adotada pela Min. Nancy Andrighi representaria uma potencialização, pelo Judiciário, das mágoas íntimas decorrentes do convívio familiar" (BRASIL, 2012).

Especificamente sobre o abandono afetivo do idoso, tendo em vista a escassa jurisprudência e a dificuldade de acesso a processos que tramitam em segredo de justiça, embora a responsabilização dos filhos ao pagamento de dano moral por abandonar seus pais, não esteja prevista na legislação, percebe-se alguns posicionamentos do Poder Judiciário.

Colaciona-se decisão sobre o tema da $8^{a}$ Câmara Cível do Tribunal de Justiça do Paraná:

\begin{abstract}
APELAÇÃO CÍVEL - AÇÃO INDENIZATÓRIA POR DANOS MATERIAIS E MORAIS - AÇÃO PROPOSTA PELA AUTORA EM FACE DE SEUS IRMÃOS - DANOS EMERGENTES - ALEGAÇÃO DE GASTOS COM A SUBSISTÊNCIA DA MÃE IDOSA - LUCROS CESSANTES - ALEGAÇÃO DE PERDA DA OPORTUNIDADE DE TER UMA PROFISSÃO, EM RAZÃO DOS CUIDADOS DEMANDADOS PELA MÃE - PLEITO DE PENSÃO MENSAL - DANOS MORAIS -ALEGAÇÃO DE DANOS MORAIS REFLEXOS, PELO SUPOSTO ABANDONO AFETIVO DA IDOSA JULGAMENTO ANTECIPADO DA LIDE - CERCEAMENTO DE DEFESA CONFIGURADO - MATÉRIAS FÁTICAS QUE EXIGIAM ADEQUADA INSTRUÇÃO PROBATÓRIA - PEDIDO SUBSIDIÁRIO DE ANULAÇÃO DA SENTENÇA - QUESTÃO PRELIMINAR - NECESSIDADE DE REABERTURA DA FASE INSTRUTÓRIA - RECURSO PROVIDO (PARANÁ, 2019)
\end{abstract}

De acordo com que foi descrito no relatório de decisão, a proposta efetuada de ação indenizatória resultante dos danos materiais e morais sofridos conforme relato da autora, foi que, após separar-se do seu marido, passou a morar com seus pais, a convite deles. O pai da autora e dos réus faleceu, sendo assim, as duas, mãe e filha, passaram a morar sozinhas, sendo que só a autora passou a amparar sua mãe, pois sua saúde já estava muito debilitada.

Consta que os réus com o tempo foram se distanciando da mãe, a qual desenvolveu depressão e Alzheimer, sua saúde estava completamente 
comprometida, e os cuidados com ela passaram a ser cada vez maiores, executados somente pela autora.

Ao mesmo tempo a saúde da autora também estava cada vez mais fragilizada, os médicos que cuidavam da sua mãe, perceberam que a autora já não tinha mais como cuidar da mãe sozinha. À vista disso, os médicos acionaram a Secretaria do Idoso, solicitando que os irmãos da autora viessem tomar providências e, em caso contrário, ajuizaria uma ação contra eles.

Sendo assim, os réus decidiram em contratar um terceiro para cuidar da mãe, todavia, essa pessoa não tinha a qualificação necessária para cuidar de uma pessoa idosa, que necessitaria de tantos cuidados, e após quatro meses resolveram internar a mãe em um asilo, sendo que em apenas dois dias depois do internamento a idosa veio a falecer.

Exemplifica-se no julgado em comento, a responsabilidade dos filhos na indenização por dano moral, não só como forma de compensação, mas visando a finalidade educativa, pois além de não cumprirem com a responsabilidade de cuidado com os pais na velhice, por amor, afeto em sinal de gratidão, esses filhos infringiram a Constituição Federal e, também, do Estatuto do Idoso.

\subsection{PROJETOS DE LEIS QUE VISAM A RESPONSABILIZAÇAO DO DESCENDENTE PELO ABANDONO DO IDOSO}

Vinsado o amparo a pessoa idosa, destaca-se vários projetos de lei que tramitam atualmente pelo Congresso Nacional a fim de responsabilizar os descendentes em relação aos ascendentes.

No Senado Federal tramita o projeto de lei $n^{\circ} 4.229$ de 2019 , de relatoria do Senador Lasier Martins, com o objetivo alterar o Estatuto do Idoso para responsabilizar civilmente o infrator, tornando ato ilícito os casos de abandono afetivo (BRASIL, 2019).

Busca-se com o Projeto de Lei, caso aprovado, o efeito pedagógico contribuindo na ação do Estado para o restabelecimento de vínculos de afetividade e para a preservação da solidariedade familiar em benefício do preceito constitucional da dignidade da pessoa humana. 
A proposta é que o artigo $1^{\circ}$ do Título II da Lei $n^{\circ} 10.741 / 03$ passe a vigorar acrescido do seguinte Capítulo XI:

Do Direito à Convivência Familiar e Comunitária:

Art. 42-A. A pessoa idosa tem direito à manutenção dos vínculos afetivos com a família e dos vínculos sociais com a comunidade, em ambientes que garantam o envelhecimento saudável.

Art. 42-B. Aos filhos incumbe o dever de cuidado, amparo e proteção da pessoa idosa.

Parágrafo único. A violação do dever previsto no caput deste artigo constitui ato ilícito e sujeita o infrator à responsabilização civil por abandono afetivo, nos termos do art. 927 da Lei n 10.406, de 10 de janeiro de 2002 (Código Civil) (BRASIL, 2019).

A tramitação do projeto encontra-se desde 01/10/2019 na Comissão de Constituição, Justiça e Cidadania, matéria com a relatoria e a última ação foi à distribuição ao Senador Wellington Fagundes, para emitir relatório.

Já na Câmara dos Deputados tramita outro Projeto de Lei n. 3145/2015, apresentado pelo Deputado Vicentinho Junior, para alterar o Código Civil de 2002 acrescentando a hipótese de deserção em casos de abandono do idoso (BRASIL, 2015).

O projeto visa alterar o Código Civil para permitir a deserdação dos filhos quando eles cometerem abandono afetivo e moral em relação a seus pais, sendo ela:

Art. $1^{\circ}$. Esta lei acrescenta inciso aos artigos 1.962 e 1.963 da Lei $n^{\circ} 10.406$, de 2002, Código Civil, de modo a possibilitar a deserdação nas hipóteses de abandono.

Art. $2^{\circ} \mathrm{O}$ artigo 1.962 do Código Civil passa a vigorar acrescido do seguinte inciso:

Art. 1.962 .

$[\ldots]$

V - abandono em hospitais, casas de saúde, entidades de longa permanência, ou congêneres;

Art. $3^{\circ} \mathrm{O}$ artigo 1.963 do Código Civil passa a vigorar acrescido do seguinte inciso:

Art. 1.963.

$[\ldots]$

V - abandono em hospitais, casas de saúde, entidades de longa permanência, ou congêneres;

Art. $6^{\circ}$ Esta lei entra em vigor na data da publicação (BRASIL, 2015).

Todavia, o Estatuto do Idoso tipifica como crime a conduta de abandono do idoso em hospitais, casas de saúde e entidades de longa permanência, com penas de detenção de 6 meses a 3 anos e multa (BRASIL, 2003) 
O Projeto encontra-se na Comissão de Direitos Humanos e Legislação Participativa e está aguardando a designação do relator, desde 19/12/19 (BRASIL, 2015).

Com mais tempo, tramita pela mesma casa legislativa o Projeto de Lei $n^{\circ}$ 4.294/2008, apresentado pelo deputado Carlos Bezerra com a finalidade precípua de atrelar à situação de abandono afetivo dos pais a previsão de indenização por danos morais, incluindo um parágrafo no artigo 1.632 do Código Civil e no artigo $3^{\circ}$ do Estatuto do Idoso.

Nas palavras do deputado em seu relatório "o envolvimento familiar não pode ser mais apenas pautado em um parâmetro patrimonialista-individualista. Deve abranger também questões éticas que habitam, o consciente e inconsciente de todo ser humano" (BRASIL, 2008).

À vista disso, o projeto de Lei 4.294/2008 pretende inserir:

Art. $1^{\circ}$ Acrescenta parágrafo ao artigo 1.632 da lei $n^{\circ} 10.406$, de 10 de janeiro de 2002 - Código Civil e ao art. da lei $n^{\circ} 10.741$, de $1^{\text {a }}$ de outubro de 2003 Estatuto do Idoso -, de modo a estabelecer a indenização por dano moral em razão do abandono afetivo.

Art. $2^{\circ} \mathrm{O}$ artigo 1.632 da lei $n^{\circ} 10.406$, de 10 de janeiro de 2002 - Código Civil - passa a vigorar acrescido do seguinte parágrafo único:

Art. $1632 \ldots$

Parágrafo único: $\mathrm{O}$ abandono afetivo sujeita os pais ao pagamento de indenização por dano moral. (NR)

Art. $3^{\circ} \mathrm{O}$ parágrafo único do art. $3^{\circ}$ da lei $\mathrm{n}^{\circ} 10.741$, de $1^{\text {a }}$ de outubro de 2003 - Estatuto do Idoso - passa a vigorar como parágrafo $1^{\circ}$, devendo ser acrescido o seguinte parágrafo $2^{\circ}$ ao artigo:

Art. $3^{\circ} \ldots$

$\S 1^{\circ}$

$\S 2^{\circ} \mathrm{O}$ abandono afetivo sujeita os filhos ao pagamento de indenização por dano moral (BRASIL, 2008).

Atualmente o Projeto encontra-se com parecer pela aprovação da Comissão de Seguridade Social e Família, dos relatores Deputada Jô Moraes e Deputado Geraldo Thadeu. (BRASIL, 2008).

\section{CONCLUSÃO}

Com fulcro na projeção realizada pelo IBGE, a população idosa aumentará consideravelmente nos próximos anos. A partir desses dados, verificou-se simultaneamente um fator positivo, do aumento da longevidade da população e por 
outro lado os desafios que esta situação representa para o país tanto nas áreas social, econômica, cultural e política.

Evidenciou-se no decorrer do presente trabalho, o dever legal de proteção do idoso e a problemática em relação a sua qualidade vida senil. No que se refere ao processo de envelhecimento, a população idosa tem direito a envelhecer com dignidade, pelas circunstâncias de vulnerabilidade que muitos se encontram, recebendo proteção da família, da sociedade e do Estado.

Diante desse quadro, premente o envolvimento governamental, familiar e social em favor do idoso, afinal, as pessoas idosas precisam ser valorizadas, pois passaram a vida trabalhando em prol da sociedade e da família, contribuindo para o desenvolvimento do país, entretanto a sociedade moderna valoriza muito a produtividade e a competividade, desse modo, tem-se como potencial produtivo a juventude, em detrimento do idoso, que já não pode ser tão útil à coletividade, atribuindo valores negativos aos idosos, transformando a velhice em algo indesejável e penoso.

Nesse viés, as pessoas idosas não têm o devido reconhecimento, e este, cabe primeiramente à família, que deve apoiar os seus desejos e necessidades, dando-lhes atenção, afeto e oportunidades para que se sintam úteis, assegurando o direito a uma vida digna em sua plenitude.

Verificou-se que após a Constituição Federal de 1988, o idoso passou a ter especial proteção do Estado e na sequência em 2003 com a criação do Estatuto do Idoso, que regulamentou a previsão Constitucional e garantiu um conjunto mais amplo de direitos aos idosos.

Por via de consequência ao amparo ao idoso, levantou-se o questionamento sobre a responsabilização dos familiares que por ação ou omissão praticam condutas lesivas contra seus idosos e que estes, poderão vir a ser processados e responsabilizados por suas atitudes, sejam elas materiais ou morais.

Mesmo que, ainda haja conflitos tanto na legislação e a jurisprudência sobre a aplicação de ressarcimento pelo abandono afetivo praticado pelo familiar, o fato de já haver decisões favoráveis acerca da responsabilização civil permitiu-se a reflexão do efetivo amparo do cumprimento das obrigações decorrentes das relações familiares, ainda que de forma educativa. 
Ademais, com o presente estudo percebeu-se que a pessoa idosa, apesar de estar protegida pela legislação brasileira, ainda sofre com as lacunas da lei e da sociedade, principalmente pela ausência de normas que se dediquem a proteger e garantir os direitos dos idosos e extinguir da nossa sociedade o descuido e a negligência familiar.

Notadamente, o presente artigo não tem como objetivo enaltecer a imposição de amar, tampouco afirmar que a afetividade deve ser um ato obrigatório nas relações familiares, mas sim que o dever de cuidar, estabelecido pela legislação, seja cumprido com responsabilidade, visto que no tema em comento, entende-se que o filho será responsabilizado quando sua conduta gerar danos aos seus pais idosos.

Neste sentido, os Projetos de Lei 4.294/08, 4.229/19 e 3145/2015 em tramitação nas casas legislativas tem o condão de positivar a indenização em decorrência do abandono afetivo inverso.

Por fim, dada a importância do tema, torna-se indispensável o debate sobre a proteção dos direitos da pessoa idosa e a efetividade deste amparo. Nesse contexto, provoca-se a reflexão da dialética familiar, que em outras palavras sugestiona-se o ciclo da vida: a base para uma boa qualidade de vida para os idosos está pautada no diálogo, no amor, na convivência, na afetividade e no respeito mútuo, nos valores passados entre pais e filhos, esperando que, em um futuro não muito distante, perceba que o cuidado e a proteção para com os idosos deve ser um ato de retribuição e mais do que isso um ato de responsabilidade.

\section{REFERÊNCIAS}

ARRUDA, Camila Rabelo de Matos Silva; BORGES, Leticia Maria de Oliveira. O direito fundamental à envelhecer com dignidade. Curitiba: Revista de Direitos Sociais, Seguridade e Previdência Social, v. 2, n. 2, jul./dez. 2016. p. 210-229.

BEAUVOIR, Simone de. A velhice. Tradução Maria Helena Franco Martins. 3. ed. Rio de janeiro: Nova fronteira, 2018. Edição do Kindle.

BORGES, Gabriel Mendes; CAMPOS, Marden Barbosa; SILVA, Luciano Gonçalves de Castro. Transição da Estrutura etário no Brasil: oportunidades e desafios para a sociedade nas próximas décadas. In: BORGES, Gabriel Mendes; ERVATTI, Leila Regina; JARDIM, Antônio de Ponte. Instituto Brasileiro de Geografia e Estatística (org.). Mudança Demográfica no Brasil no Início do Século XXI. 3. ed. Rio de 
Janeiro: IBGE, 2015. n.p. Disponível em: https://biblioteca.ibge.gov.br/visualizacao/ livros/liv93322.pdf. Acesso em: 24 abr. 2020.

BORGES, Gabriel Mendes; ERVATTI, Leila Regina; JARDIM, Antônio de Ponte. Instituto Brasileiro de Geografia e Estatísticas (org.). Mudança demográfica no Brasil no início do século XXI: subsídios para as projeções da população. 3. ed. Rio de Janeiro: IBGE, 2015. p. 01-156. Disponível em: https://biblioteca.ibge.gov.br/visualizacao/livros/liv93322.pdf. Acesso em: 24 abr. 2020.

BRAGA, Melissa Vianna. Curso de Direito do Idoso. São Paulo: Atlas, 2011. Ebook.

BRASIL. Assembleia Legislativa. Projeto de Lei $n^{\circ}$ 3145/2015, de 29 de setembro de 2015. Altera o Código Civil para permitir a deserdação (exclusão da herança) dos filhos quando eles cometerem abandono afetivo e moral em relação a seus pais. Disponível em: https://www.camara.leg.br/proposicoesWeb/ fichadetramitacao?idProposicao=1805805. Acesso em: 07 set. 2020.

BRASIL. Assembleia Legislativa. Projeto de Lei $\mathbf{n}^{\circ}$ 4229/2019. Brasília, 06 ago. 2019. Altera a Lei $n^{\circ} 10.741$, de $1^{\circ}$ de outubro de 2003 (Estatuto do Idoso), para dispor sobre o direito da pessoa idosa à convivência familiar e comunitária, bem como para prever a hipótese de responsabilidade civil por abandono afetivo. Disponível em: https://www25.senado.leg.br/web/atividade/materias//materia/137919. Acesso em 07 set. 2020.

BRASIL. Assembleia Legislativa. Projeto de Lei $n^{\circ}$ 4294/2008, de 12 de novembro de 2008. Acrescenta parágrafo ao art. 1.632 da Lei $n^{0} 10.406$, de 10 de janeiro de 2002 - Código Civil e ao art. $3^{\circ}$ da Lei $n^{\circ} 10.741$, de $1^{a}$ de outubro de 2003 - Estatuto do Idoso, de modo a estabelecer a indenização por dano moral em razão do abandono afetivo. Disponível em: https://www.camara.leg.br/proposicoesWeb/ fichadetramitacao?idProposicao=415684. Acesso em: 07 set. 2020.

BRASIL. Constituição 1988. Constituição da República Federativa do Brasil de 1988. Brasília, DF: Presidência da República, (2020). Disponível em: http://www.planalto.gov.br/ccivil_03/constituicao/constituicao.htm. Acesso em: 1 abr. 2020.

BRASIL. Estatuto do idoso: Lei Federal n 10.741, de 01 de outubro de 2003. Brasília, DF: Secretaria Especial dos Direitos Humanos. Disponível em: http://www.planalto.gov.br/ccivil_03/leis/2003/l10.741.htm. Acesso em: 1 abr. 2020.

BRASIL. Lei $\mathbf{n}^{0}$ 10.406, de 10 de janeiro de 2002. Código Civil. Diário Oficial da União: seção 1, Brasília, DF, a. 139, n. 8, p. 1-74, 11 jan. 2002. Disponível em: http://www.planalto.gov.br/ccivil_03/leis/2002//10406compilada.htm. Acesso em: 1 abr. 2020 
BRASIL. Ministério do Desenvolvimento Social. Estratégia Brasil amigo da pessoa idosa: a pessoa idosa no brasil. Brasília: MDS, 2018. Disponível em: http://mds.gov.br/assuntos/brasil-amigo-da-pessoa-idosa/estrategia-1. Acesso em: 21 abr. 2020.

BRASIL. Superior Tribunal de Justiça. Recurso Especial $n^{\circ}$ 1159242. Civil e Processual Civil. Família. Abandono Afetivo. Compensação Por Dano Moral. Possibilidade. Brasília, DF: Superior Tribunal de Justiça, DF, 2012. Disponível em: https://scon.stj.jus.br/SCON/jurisprudencia/doc.jsp. Acesso em: 14 set. 2020.

CAVALIERI FILHO, Sergio. Programa de Responsabilidade Civil. 13. ed. São Paulo: Atlas, 2019. E-book.

DIAS, Maria Berenice. Manual do direito de família. 11. ed. São Paulo: Revista dos Tribunais, 2016.

LEITE, Mateus de Oliveira Fornasier; Flavia Piva Almeida. A exclusão social do idoso no ambiente urbano. Revista de Direito da Cidade, Rio de Janeiro, v. 10, 2018.

LIMA, Joyce Cibelly de Morais. Abandono afetivo inverso: a responsabilidade civil dos filhos em relação aos pais idosos. Belo Horizonte: IBDFAM, 2015. Disponível em: https://www.ibdfam.org.br/artigos/1055/Abandono+afetivo+inverso+ responsabilidade+civil+dos+filhos+em+rela/. Acesso em: 03 set. 2020.

LÔBO, Paulo. Direito civil: Famílias. 9. ed. São Paulo: Saraiva, 2019. E-book.

PACHA, Andréa. O direito de envelhecer cercado de amor. Jornal O Globo. Rio de Janeiro, 05 nov. 2018. Disponível em:https://oglobo.globo.com/sociedade/artigodireito-de-envelhecer-cercado-de-amor-22453034/. Acesso em 15 abr. 2020.

PAMPLONA FILHO, Rodolfo, GAGLIANO, Pablo Stolze. Novo curso de direito civil: direito de família. 7. ed. São Paulo: Editora Saraiva, 2017. E-book.

PARANÁ. Tribunal de Justiça do Estado. Apelação Cível n 1539164-5. Relator: Desembargador Gilberto Ferreira. Londrina, PR. 2017. Disponível em: https://portal.tjpr.jus.br/jurisprudencia/j/12341277. Acesso em: 14 set. 2020.

PEREIRA, Rodrigo da Cunha. Direito das famílias. Rio de Janeiro: Forense, 2020. E-book.

RAMOS, Paulo Roberto Barbosa. Curso de direito do idoso. São Paulo: Editora Saraiva, 2014. E-book.

SOMMER, Aleissa de Lima Amorin; OLIVEIRA Victoria Georgia Cheuiche; DUARTE, Francielle Pires. Abandono afetivo inverso. Revista Jurídica Direito, Sociedade e Justiça, Dourados, 2017.

TARTUCE, Flávio. Direito civil: direito das obrigações e responsabilidade cível. 15. ed. Rio de Janeiro: Saraiva, 2020. E-book. 
TARTUCE, Flávio. Direito civil: direito de família. 15. ed. Rio de Janeiro: Forense, 2020. E-book.

VENOSA, Sílvio de Salvo. Direito civil: obrigações e responsabilidade civil. 20. ed. São Paulo: Atlas, 2019. E-book.

VIEGAS, Cláudia Mara de Almeida Rabelo; BARROS, Marília Ferreira de. Abandono afetivo inverso: o abandono do idoso e a violação do dever de cuidado por parte da prole. Caderno do Programa de Pós-graduação em Direito da UFRGS. Porto Alegre, v. 11, n. 3, p. 168-201, 2016.

Artigo recebido em: 06/10/2020

Artigo aceito em: 18/11/2020

Artigo publicado em: 29/07/2021 